\title{
Determination of Paroxetine in Pharmaceutical Preparations Using HPLC with Electrochemical Detection
}

\author{
Nitasha Agrawal ${ }^{1}$, Josep Esteve-Romero ${ }^{2}$, Neeti Prakash Dubey ${ }^{3}$, Abhilasha Durgbanshi ${ }^{4}$, \\ Devasish Bose ${ }^{1}$, J. Peris-Vicente ${ }^{2}$ and S. Carda-Broch ${ }^{*}, 2$ \\ ${ }^{I}$ Department of Criminology and Forensic Sciences, Dr. H.S. Gour University, Sagar, India \\ ${ }^{2}$ Àrea de Química Analítica, Universitat Jaume I, 12080, Castelló, Spain \\ ${ }^{3}$ Regional Forensic Science Laboratory, Dharmshala, Himachal Pradesh, India \\ ${ }^{4}$ Department of Applied Chemistry, Institute of Technology, Banaras Hindu University, Varanasi, India
}

\begin{abstract}
A reliable and sensitive high performance liquid chromatographic method for the determination of widely prescribed antidepressant has been developed. Paroxetine is a potent selective serotonin reuptake inhibitor used for the treatment of depression and various mood disorders. The optimum mobile phase was prepared using a combination of $40 \%$ acetonitrile and phosphate buffer $0.01 \mathrm{M}$ to $\mathrm{pH} 3$ and running under isocratic mode at a flow rate of $1.0 \mathrm{ml} / \mathrm{min}$. with electrochemical detection at $0.9 \mathrm{~V}$. The applicability of the developed method is in the field of quality control as well as for monitoring the level of drug at various concentrations during synthesis of the parent drug. The suggested methodology was validated following the guidelines of the FDA in terms of: sensitivity (LOD and LOQ, 0.005 and $0.01 \mathrm{ng} / \mathrm{mL}$, respectively), linearity between $0.5-50 \mathrm{ng} / \mathrm{mL}\left(\mathrm{r}^{2}>0.9999\right)$, inter- and intraday precision $(<0.259 \%$ and $<0.538 \%)$, robustness (less than 5.0\%) and recovery $(99.7-100.7 \%$ ). The developed method is specific, rapid (less than $10 \mathrm{~min}$ ), precise, reliable, accurate, cheap and suitable for routine analysis for the determination of paroxetine in pharmaceutical preparations.
\end{abstract}

Keywords: Paroxetine, HPLC, electrochemical detection, pharmaceutical.

\section{INTRODUCTION}

In the last few years prescription of antidepressants has increased many folds. The increase in the number of patients suffering with depression has indeed elevated the sale of antidepressants. The new drugs that enhance serotoninergic neurotransmission by potent and selective inhibition of serotonin are highest amongst the prescribed antidepressants, they are known as selective serotonin re-uptake inhibitors (SSRIs) [1]. Paroxetine, (-)-trans-4-(4-fluorophenyl)-3-(3, 4methylenedioxy-phenoxymethyl) piperidine, is one of the SSRIs used widely as an antidepressant drug alone, or in combination, with other drugs [2]. Paroxetine is comparable to the tricyclic antidepressants in their clinical efficacy, however, it is safer and has greater acceptance by the patients. Paroxetine is devoid of sedative effect and remarkably safe in overdose also. It takes 5.2 hours to reach the peak plasma level, with extended half life ( 21 hours) that allowed the introduction of formulations for once daily dosing. These combined qualities made paroxetine the most widely prescribed antidepressants [3]. It is normally used in the treatment of clinical depression, obsessive-compulsive disorder, and panic disorder [4]. In a survey performed by National Drug Code Health (Atlanta, GA, USA) in 2002,

*Address correspondence to this author at the Àrea de Química Analítica, Universitat Jaume I, 12080, Castelló, Spain; Tel: 0034964728095;

E-mail:scarda@uji.es paroxetine was one of the top 200 prescriptions for 2002 by number of U.S. prescriptions dispensed

The increase in the demand of the antidepressant drug has unfortunately invited supply of fake or counterfeit drugs in the local markets just to fulfill the requirement and maintain the low cost production which in turn can be very harmful for the patients consuming these drugs unknowingly. In many developing and under developed countries, there are no proper govern on quality of the drugs supplied in the market under non- certified trade names which are readily available at the pharmacists shop and other medical stores.

During the literature survey it was also found that along with its benefits in treatment of depression, paroxetine do possess some serious health risks. Patients with depression are at a high risk of suicide attempts [5]. The European Medicines Agency's (EMEA) Committee for Medicinal Products for Human Use (CHMP) also issued a warning regarding prescription of paroxetine to children and also asked to closely monitor adult patients showing suicidal tendency and/or suicidal thoughts. Paroxetine is also related with withdrawal symptoms and that is why it is recommended to gradually reduce the dose over several weeks or months if decision of withdrawal is made [6]. A survey carried out by Food and Drug Administration in 2004 on children prescribed with paroxetine showed 2.7 -fold raise in suicide behavior and ideation as compared to placebo. The 
trend for increased suicidality was observed in both trials for depression and for anxiety disorders [7].

Paroxetine and its metabolites in human plasma, human serum, and in pharmaceutical preparations have been quantified either by high-performance liquid chromatography (HPLC) or by gas chromatography. Several methods have been developed for the determination of paroxetine in plasma, including HPLC with ultraviolet $[5,6]$, fluorescence (without or with derivatization using dansylchloride) [7-9], mass spectroscopy (MS) [10, 11], diode array detection [12,13], or gas chromatography with MS detection [14,15] and applied therapeutic drug level monitoring. Only few methods have been published for the simultaneous determination of paroxetine and its metabolites in plasma, using HPLC with UV [2,16]; or applied to pharmacokinetic, therapeutic drug level monitoring, toxicological screening or forensic cases [17].

The purpose of this work is to develop a rapid, simple, cost effective and selective HPLC procedure for the screening of paroxetine in pharmaceutical preparations, which is one of the most popular antidepressant widely prescribed for the treatment of depression and related mood disorders, using $\mathrm{C} 18$ column and electrochemical detection. The suggested method must be validated following FDA indications in terms of selectivity, sensitivity, linearity, repeatability, reproducibility, robustness and recovery [18].

\section{EXPERIMENTAL}

\subsection{Materials}

Standard of paroxetine (purity $>99.99 \%$ ) was kindly gifted from Zydus Health care, Sikkim, India. Other pharmaceutical samples (Depox, Pari-CR, Parotin, Pexep, Raxit, etc) were procured from the pharmacists of local market at Sagar, India. Some of them were gifted by medical practitioners. Paroxetine-STADA was procured from pharmacist in Castellon, Spain. HPLC grade acetonitrile and methanol were purchased from Scharlau, Barcelona. Sodium dihydrogenphosphate monohydrate, potassium chloride, and $\mathrm{HCl}$ were from Panreac, Barcelona. $\mathrm{NaOH}$ was from Scharlab, Barcelona (all were $>99 \%$ purity). Ultrapure water used was prepared by using Millipore throughout the study.

\subsection{Instrumentation}

An Agilent Technologies chromatograph (Model HP1100, Palo Alto, CA, USA), equipped with a quaternary pump, an autosampler, a UV-Vis and electrochemical (Model HP 1049A) detectors was used. Monitoring was carried out at $230 \mathrm{~nm}$ with UV detector, and $0.9 \mathrm{~V}$ with electrochemical detector using $\mathrm{Ag} / \mathrm{AgCl}$ electrode as a reference electrode and glassy carbon as the working electrode. A Shimadzu double beam UV-Vis. Spectrophotometer UV-210 system shimadzu corporation (Kyoto, Japan) was used to measure the spectra. Another chromatographic system i.e. Shimadzu Prominence HPLC, Shimadzu Corporation, equipped with an isocratic pump LC-20 AT prominence pump, an autosampler SIL-20AC and a diode array detector SPD-M20A (190-800 nm) was used. The flowrate was $1.0 \mathrm{ml} / \mathrm{min}$ and the injection volume of autosampler was set at $20 \mu \mathrm{l}$. A Kromasil C18 column $(5 \mu \mathrm{m}$ particle size, $120 \mathrm{~mm} \times 4.6 \mathrm{~mm}$ i.d.) Scharlab, was employed for the analytical separation. The chromatographic data was acquired by means of personal computer connected to the chromatograph by means of Shimadzu LC workstation "LC solution software", version1.22SP1 and "HP Chemstation" for Agilent HPLC.

The $\mathrm{pH}$ of the mobile phase was measured with a Crison pH meter (Model micro pH 2001, Barcelona), equipped with a combined $\mathrm{Ag} / \mathrm{AgCl} /$ glass electrode Crison GLP 22, Barcelona.

\subsection{Standard and Pharmaceutical Sample Preparation}

The commercially available tablets of paroxetine were weighed and powdered using pastel mortars. A portion of the powder equivalent to about $10 \mathrm{mg} / \mathrm{ml}$ was weighed accurately, transferred to a $100 \mathrm{~mL}$ calibrated flask and suspended in methanol for analysis. The samples were filtered through a $0.45 \mu \mathrm{m}$ nylon membrane filter, and then further diluted before injection.

\subsection{Mobile Phase Preparation}

For mobile phase preparation, various combinations of methanol:water and acetonitrile:water were prepared buffered to $\mathrm{pH} 7$, pH 5 or pH 3 using $0.01 \mathrm{NaH}_{2} \mathrm{PO}_{4}$ buffer salt, $0.001 \mathrm{M} \mathrm{KCl}$ and adjusting the $\mathrm{pH}$ using $\mathrm{NaOH}$ or $\mathrm{HCl}$. The results obtained showed better response in acetonitrile:water combinations, buffered to $\mathrm{pH}$ 3. All solvents were filtered through $0.45 \mu \mathrm{m}$ filter paper and degassed.

\section{RESULT AND DISCUSSION}

\subsection{Development and Optimization of the HPLC Method}

The dissociation constant $(\mathrm{pKa})$ for paroxetine is 9.9 (Table 1) which suggests that it is a non-protonated compound and falls beyond the working $\mathrm{pH}$ range of column (3 - 7), still to check the effect of $\mathrm{pH}$ paroxetine was injected using the three selected $\mathrm{pH}$ i.e. (3; 5 and 7$)$, no change was observed in retention time but on the basis of other chromatographic parameters i.e. efficiency $(\mathrm{N})$ and asymmetry (B/A), pH 3 was selected for the further study. The partition coefficient $(\log \mathrm{P}(\mathrm{o} / \mathrm{w}))$ of paroxetine is 3.95 ; suggesting that the compound is highly hydrophobic in nature. Based on that, various mobile phase combinations such as methanol: water and acetonitrile: water at different concentrations was used (Table 2). The results obtained using combination of acetonitrile: water gave better chromatographic parameters i.e. peak shape (more Gaussian), asymmetry (close to 1.000), efficiency (higher) and retention time (lower, but $>2.00$ $\min )$. So for further analysis combination of acetonitrile: water (40:60) buffered to $\mathrm{pH} 3$ was selected (Fig. 1). Under these conditions, paroxetine was eluted in less then $10 \mathrm{~min}$, lower than the time obtained in previous works $[6,7,17]$.

\subsection{Study of Oxidation Potential}

Paroxetine is the only drug amongst SSRIs which is electrochemically active. The benefit of such kind of compound is that the interference from similar group is nullified, which assures the selectivity of the method. Then the methodology show higher specificity than previous works based on HPLC coupled to UV-Visible [5,6,15,17], fluorescence $[7,9,12,16]$ or MS detectors $[10,11]$. 


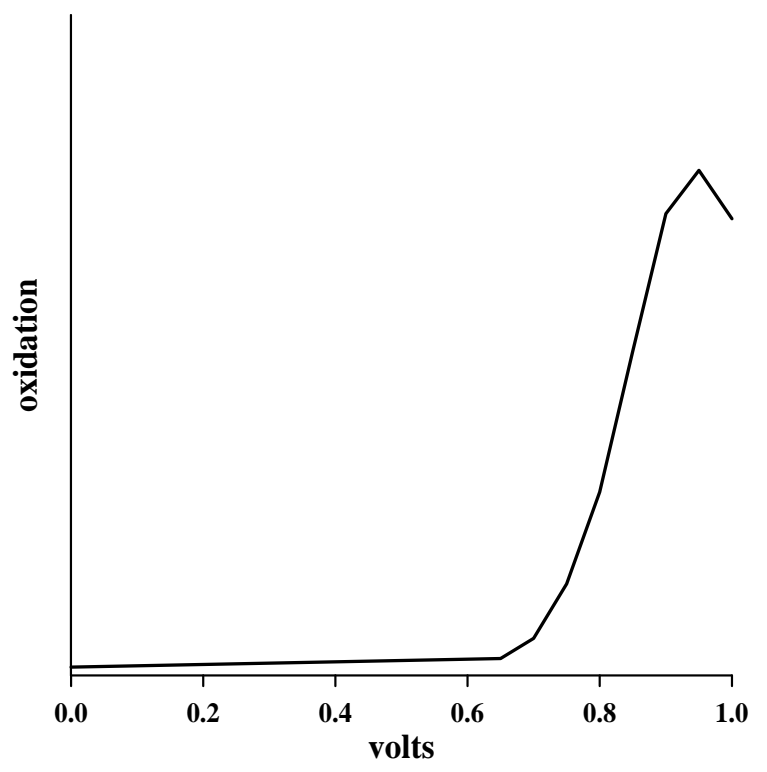

Fig. (1). Standard chromatogram of a standard solution of 10 $\mathrm{ng} / \mathrm{mL}$ of paroxetine using the optimum mobile phase comprising

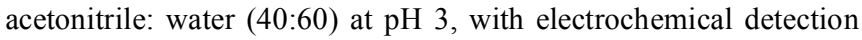
at $0.9 \mathrm{~V}$.

Table 1. Structure and Physical Properties of Paroxetine

\begin{tabular}{|c|c|c|}
\hline Structure & $\begin{array}{c}\text { Dissociation } \\
\text { Constant }\end{array}$ & $\begin{array}{c}\text { Partition } \\
\text { Coefficient }\end{array}$ \\
\hline \hline
\end{tabular}

Table 2. Retention Behavior of Paroxetine Using Various Combination of Methanol, Acetonitrle and Water Used as Mobile Phase

\begin{tabular}{|c|c|c|c|}
\hline S. No. & Mobile Phase & Ratio & Retention Time (min) \\
\hline \hline 1. & MeOH: $\mathrm{H}_{2} \mathrm{O}$ & $75: 25$ & 10.42 \\
\hline 2. & MeOH: $\mathrm{H}_{2} \mathrm{O}$ & $25: 75$ & 13.84 \\
\hline 3. & MeOH: $\mathrm{H}_{2} \mathrm{O}$ & $100: 0$ & 7.6 \\
\hline 4. & MeOH: $\mathrm{H}_{2} \mathrm{O}$ & $50: 50$ & 7.1 \\
\hline 5. & MeOH: $\mathrm{H}_{2} \mathrm{O}$ & $80: 20$ & - \\
\hline 6. & Acetonitrile $: \mathrm{H}_{2} \mathrm{O}$ & $30: 70$ & 14.9 \\
\hline 7. & Acetonitrile: $\mathrm{H}_{2} \mathrm{O}$ & $40: 60$ & 6.6 \\
\hline 8. & Acetonitrile: $\mathrm{H}_{2} \mathrm{O}$ & $45: 55$ & 5.2 \\
\hline 9. & Acetonitrile: $\mathrm{H}_{2} \mathrm{O}$ & $50: 50$ & 3.2 \\
\hline 10. & Acetonitrile $: \mathrm{H}_{2} \mathrm{O}$ & $60: 40$ & 2.8 \\
\hline
\end{tabular}

In order to select the optimum oxidation potential for paroxetine, hydrodynamic voltammogram was plotted (Fig. 2). The potential applied varies between +0.1 to $+0.9 \mathrm{~V}$, in $0.1 \mathrm{~V}$ steps up to $0.6 \mathrm{~V}$ and then after at an interval of 0.05 $\mathrm{V}$. By observing the results obtained for paroxetine it was concluded that paroxetine starts oxidizing above $0.5 \mathrm{~V}$ and reaches the maximum at $0.9 \mathrm{~V}$ following which a reduction is observed. Therefore on the basis of results obtained $0.9 \mathrm{~V}$ was selected as the potential for further study.

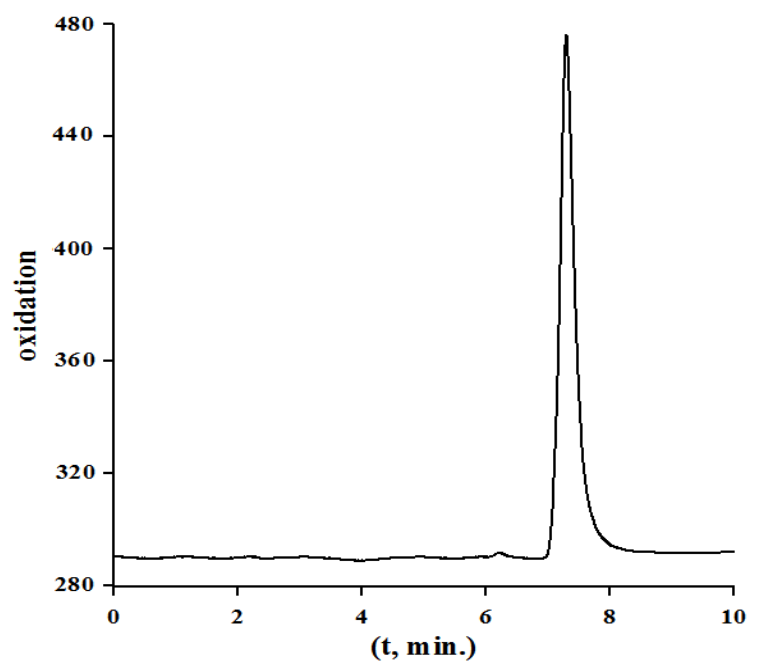

Fig. (2). Oxidation curve for paroxetine

\subsection{Linearity and Limit of Detection}

Calibration curves were constructed for paroxetine using the areas of the chromatographic peaks observed at eight increasing concentrations, each calibration level was analyzed 6 times. The concentrations were in the range 0.5 $50 \mathrm{ng} / \mathrm{ml}$ using electrochemical detection, while 50-500 $\mathrm{ng} / \mathrm{ml}$ for UV. The calibration parameters (slopes and intercepts) using electrochemical detection were higher than those obtained with UV detection, and then electrochemical detection was selected for the analysis of paroxetine. The regression curve was:

$\mathrm{A}=(572 \pm 2)[$ paroxetine $(\mathrm{ng} / \mathrm{mL})]+(2.3 \pm 0.1) \mathrm{r}^{2}>0.9999$

The limit of detection (LOD) and quantification (LOQ) for the drug were determined with the $3 \mathrm{~s}$ and $10 \mathrm{~s}$ criterion respectively, using a series of 10 solutions (10 to $0.01 \mathrm{ng} / \mathrm{ml}$ ) containing low concentrations of the drug to calculate $s$. The results were based not only on the standard deviation of the response, but also on the slope of the calibration curve. LOD $(0.005 \mathrm{ng} / \mathrm{mL})$ and LOQ $(0.01 \mathrm{ng} / \mathrm{mL})$ indicate that the procedure is sensitive enough for the routine pharmaceutical and biological analysis. Sensitivity and linearity were higher than obtained in previously published works $[5$, 6,7,9,10,12,15-17].

\subsection{Repeatability and Intermediate Precision}

Repeatability was evaluated by analyzing five replicates of three standard solutions in increasing concentrations (1; 2.5 and $5 \mathrm{ng} / \mathrm{mL}$ ), and reproducibility was evaluated using the same standard solutions five different days over a period of two months. The precision was determined as the CV (\%) of the results. Intraday precision was: $0.259 ; 0.144$ and $0.119 \%$ (respectively), whereas interday precision was: 
$0.538 ; 0.225$ and $0.135 \%$ (respectively). The low variability and high precision of the results obtained in different days are evident, which indicate the usefulness of the method. The method was more precise than in other previously published papers $[5,6,7,9,10,11,12,15-17]$.

(a)

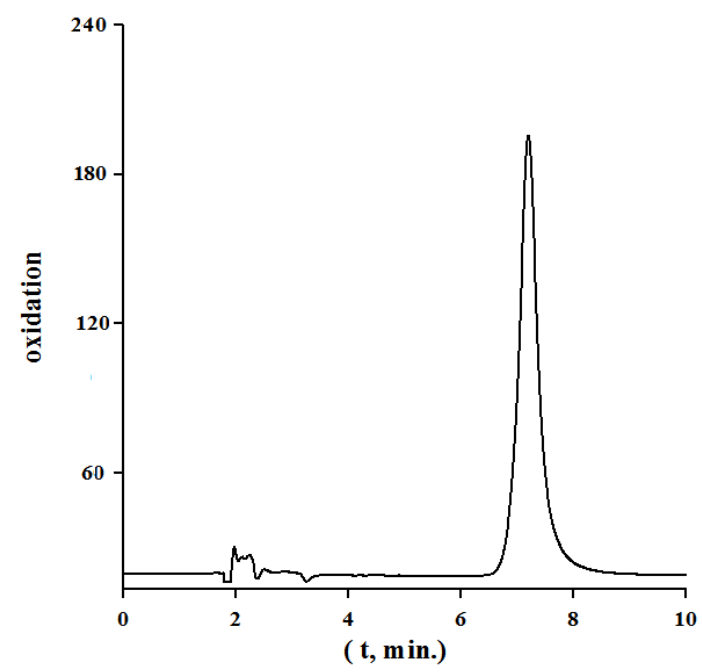

(b)

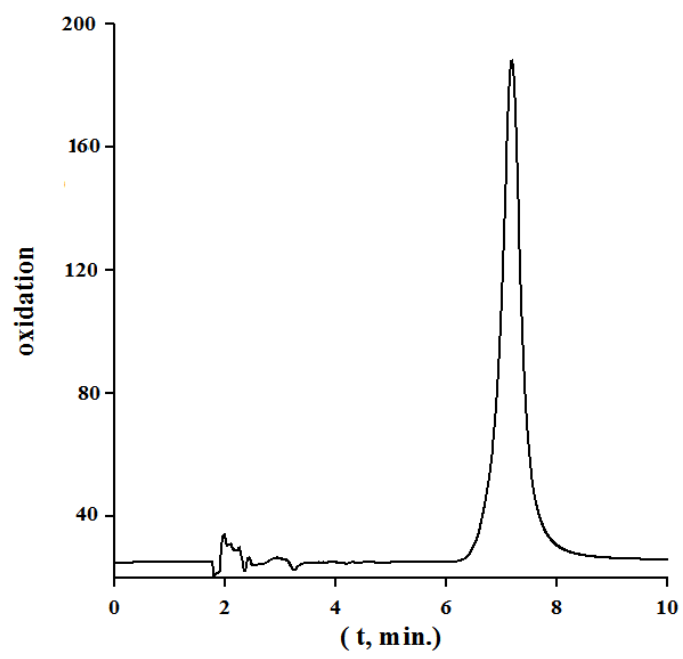

Fig. (3). Chromatograms corresponding to paroxetine in pharmaceutical preparations: (a) Pharmaceutical containing paroxetine (Raxit) procured from Spain. (b) Pharmaceutical containing paroxetine (Parotin) procured from India.

\subsection{Robustness}

The developed method was found to be robust based on the fact that the small deliberate changes in the conditions did not have any significant effect on the chromatographic behavior of the analyte. The chromatographic conditions such as concentration of mobile phase and value of $\mathrm{pH}$ were slightly altered. The effects of slight changes in applied detection potential and flow-rate were also studied. Variation of the flow rate had stronger influence on the retention of the studied compounds than other selected parameters. However, the variations in all the parameters (R.S.D.) had no significant effect on retention time $(<3.5 \%)$, efficiency $(<$ $0.4 \%)$ and asymmetry $(<6.8 \%)$. The results obtained are summarized in Table $\mathbf{3}$.

\subsection{Analysis of Paroxetine in Pharmaceutical Preparations}

The contents of some pharmaceutical formulations commercially available in India and Spain were determined using the developed method. Paroxetine in India and Spain sold under various trade names gave the result similar to that mentioned on the wrapper. All the available drugs were diluted to inject in the chromatographic system an amount of analyte into the linear range. In the obtained chromatograms, the paroxetine was eluted without interferences from other substances of the matrix, then proving the selectivity of the suggested methodology. The results showed satisfactory recoveries (99.7 - 100.7\%), as shown in Table 4. Accuracy obtained using this method were higher than previously published works $[5-7,9-12,15-17]$. Fig. (3) shows two chromatograms corresponding to paroxetine in pharmaceutical preparations.

\section{CONCLUSIONS}

The results obtained from the above study indicates that the HPLC procedure developed herein could easily be used for the determination of paroxetine in pharmaceutical preparations with an analysis time below 10 min., using 40\% acetonitrile and $60 \%$ water, buffered at $\mathrm{pH} 3$. The procedure is sensitive enough to monitor paroxetine in clinical samples and pharmaceuticals. The high values of LOD and LOQ make the method more applicable for quality control labs. The method was successfully applied for the analysis of paroxetine in pharmaceutical preparations with good accuracy and precision. The developed method is fast, robust, easy to handle as well as per sample analysis cost is also low. The next step of the research would be to apply this methodology to the analysis of clinical and biological

Table 3. Robustness Study

\begin{tabular}{|c|c|c|c|c|c|}
\hline Chromatographic Parameter & Variation & Retention Time (min) & $\mathbf{N}$ & $\mathbf{B} / \mathbf{A}$ & Peak Area \\
\hline $\begin{array}{l}\text { Acetonitrile amount (\%) of } \\
\text { mobile phase }\end{array}$ & $38-42$ & $\begin{array}{l}7.23 \pm 0.15 \\
\quad(2.1 \%)\end{array}$ & $\begin{array}{c}2653 \pm 5 \\
(0.2 \%)\end{array}$ & $\begin{array}{l}1.89 \pm 0.13 \\
(6.8 \%)\end{array}$ & $\begin{array}{l}2939 \pm 10 \\
(0.3 \%)\end{array}$ \\
\hline $\begin{array}{l}\text { Flow rate } \\
(\mathrm{mL} / \mathrm{min})\end{array}$ & $0.9-1.1$ & $\begin{array}{c}7.2 \pm 0.3 \\
(3.5 \%)\end{array}$ & $\begin{array}{c}2653 \pm 4 \\
(0.2 \%)\end{array}$ & $\begin{array}{l}1.94 \pm 0.05 \\
\quad(2.3 \%)\end{array}$ & $\begin{array}{c}2928 \pm 5 \\
(0.2 \%)\end{array}$ \\
\hline
\end{tabular}


Table 4. Absolute Recovery of Paroxetine in Various Pharmaceutical Preparations

\begin{tabular}{|c|c|c|c|}
\hline S. No. & Commercially Procured Pharmaceutical Preparation & Found $(\boldsymbol{\mu g} / \mathbf{m l})$ Mean $\pm \mathbf{S . D .}$ & Absolute Recoveries $(\%$ Mean) \\
\hline \hline 1. & Depox & $9.6 \pm 1.9$ & $100.5 \%$ \\
\hline 2. & Pari-CR & $9.5 \pm 1.3$ & $99.7 \%$ \\
\hline 3. & Parotin & $9.5 \pm 1.6$ & $99.8 \%$ \\
\hline 4. & Pexep & $9.6 \pm 1.7$ & $100.4 \%$ \\
\hline 5. & Raxit & $9.6 \pm 1.6$ & $100.7 \%$ \\
\hline
\end{tabular}

samples, as serum, plasma and urine; and the analysis of paroxetine derivatives.

\section{CONFLICT OF INTEREST}

The authors confirm that this article content has no conflicts of interest.

\section{ACKNOWLEDGEMENTS}

Nitasha Agrawal thanks University Grants Commission, (M.H.R.D. and Government of India) for providing with Junior Research Fellowship.

\section{REFERENCES}

[1] C. Salgado-Petinal, J. P.; Lamas, C.; Garcia-Jares. Rapid screening of selective serotonin reuptake inhibitors in urine samples using solid phase micro-extraction gas chromatography- mass spectrometry. J. Anal. Bioanal. Chem., 2005, 382, 1351-1359.

[2] Athanasiou, N. V.; Politou, J. A.; Koupparis, M.; Spyropoulos, J. Development and validation of an HPLC method, with fluorescence detection, for simultaneous determination of paroxetine \& its metabolites in plasma. J. Liq. Chromatogr. Relat. Technol., 2007, 30, 1641-1655.

[3] Sharma, M. C.; Sharma, S. Validated simultaneous spectrophotometric estimation of paroxetine HCL bulk and tablet dosage form using ferric chloride. J. Optoelectro. Biomed. Mater., 2010, $2,185-189$

[4] RxList. http://www.rxlist.com/top200.htm [Accessed on 23-03-11].

[5] Foglia, J. P.; Sorisio, D.; Kirshner, M.; Pollock, B. G. Quantitative determination of paroxetine in plasma by high- performance liquid chromatography and ultraviolet detection, J. Chromatogr. B., 1997, 693, 147-151.

[6] Knoeller, J.; Vogt- Schenkel, R.; Brett, M.A. A simple and robust high-performance liquid chromatography method for the determination of paroxetine in human plasma, J. Pharma. Biomed. Anal., 1995, 13, 635-638.

[7] Shin, J.G.; Kim, K.A.; Yoon, Y.R.; Cha, I.J.; Kim, Y.H.; Shin, S.G. Rapid simple high performance liquid chromatographic determination of paroxetine in human plasma. J. Chromatogr., 1998, 713, 452-456.

[8] Brett, M.A.; Dierdorf, H.D.; Zussman, B.D.; Coates, P.E. Determination of paroxetine in human plasma, using highperformance liquid chromatography with fluorescence detection, $J$. Chromatogr. Biomed. Appl., 1987, 63, 438-444.

[9] Lucca, A.; Gentilini, G.; Lopez-Silva, S.; Soldarini, A. Simultaneous determination of human plasma levels of four selective serotonin reuptake inhibitors by HPLC. Ther. Drug Monit., 2000, 22, 271-276.

[10] He, J.; Zhou, Z.L.; H.D. Li, Simultaneous determination of fluoxetine, citalopram, paroxetine, venlafaxine in plasma by high performance liquid chromatography electrospray ionization mass spectrometry. J. Chromatogr. B., 2005, 820, 33-39.

[11] Naidong, W.; Eerkes, A. Development and validation of a hydrophilic interaction liquid chromatography-tandem mass spectrometric method for the analysis of paroxetine in human plasma. Biomed. Chromatogr., 2004, 18, 28-36.

[12] Titier, K.; Castaing, N.; Scotto-Gomez, E.; Pehourcq, F.; Moore, N.; Molimard, M. High-performance liquid chromatographic method with diode array detection for identification and quantification of the eight new antidepressants and five of their active metabolites in plasma after overdose. Ther. Drug Monit., 2003, 25, 581-587.

[13] Duverneuil, C.; de la Grandmaison, G.L.; de Mazancourt, P.; Alvarez, J.C. A high performance liquid chromatography method with photo diode array UV detection for therapeutic drug monitoring of the nontricyclic antidepressant drugs. Ther. Drug Monit., 2003, 25, 565-573.

[14] Leis, H.J.; Windischhofer, W.; Fauler, G. Improved sample preparation for the quantitative analysis of paroxetine in human plasma by stable isotope dilution negative ion chemical ionization gas chromatography-mass spectrometry. J. Chromatogr. B., 2002, 779, 353-357.

[15] Wille, S. M. R.; Maudens, K.E.; Van Peteghem, C.H.; Lambert, W.E.E. Development of a solid phase extraction for 13 new generation antidepressants and their active metabolites for gas chromatographic-mass spectrometric analysis. J. Chromatogr. A., 2005, 1098, 1-2

[16] Kristoffersen, L.; Bugge, A.; Lundanes, E.; Slordal, L. Simultaneous determination of citalopram, fluoxetine, paroxetine and its metabolites in plasma and whole blood by highperformance liquid chromatography with ultraviolet and fluorescence detection. J. Chromatogr. B., 1999, 734, 222-246.

[17] Molander, P.; Thomassen, A.; Kristoffersen, L.; Greibrokk, T.; Lundanes, E. Simultaneous determination of citalopram, fluoxetine, paroxetine and their active metabolites in plasma by temperatureprogrammed packed liquid chromatography with on-column focusing of large injection volumes. J. Chromatogr. B., 2002, 766 (1), 77-87.

[18] Rambla-Alegre, M.; Marco-Peiró, S.; Peris-Vicente, J.; BeltranMartinavarro, B.; Collado-Sánchez, M.A.; Carda-Broch, S.; Esteve-Romero, J. Analytical determination of hydroxytyrosol in olive extract samples by micellar liquid chromatography. Food Chem., 2011, 129, 614-618. 